\title{
Pattern of Eye Diseases among Commercial Intercity Vehicle Drivers in Nigeria
}

\author{
Bola J Adekoya' FMCOphth, FWACS, Joshua F Owoeye ${ }^{2}$ FWACS, Feyi G. Adepoju² FMCOphth, \\ FWACS, Ayotunde I. Ajaiyeoba ${ }^{1}$, FMCOphth, FWACS \\ ${ }^{1}$ Department of Ophthalmology, Lagos State University Teaching Hospital, Ikeja, Lagos, Nigeria \\ ${ }^{2}$ Department of Ophthalmology, University of Ilorin Teaching Hospital, Ilorin, Kwara State, Nigeria
}

\section{SUMMARY}

Objective: To determine the pattern of eye diseases among commercial intercity vehicle drivers (CIVDs) in Ilorin, Nigeria.

Design: A cross-sectional descriptive study.

Methodology: Out of the estimated 450 drivers operating in the five major motor parks for CIVDs in Ilorin, 399 consecutive drivers participated in the study. Structured questionnaires were administered and ocular examinations were done.

Results: The common ocular conditions seen were presbyopia $(28.3 \%)$, allergic conjunctivitis $(22.6 \%)$, pingueculae $(18.0 \%)$, ocular hypertension (8.8\%), pterygium $(8.3 \%)$, cataract $(7.8 \%)$, and uncorrected refractive error $(6.0 \%)$. Visual impairment, based on legally required standard for commercial drivers in Nigeria, was found in $11.5 \%$ of the participants, while $3.3 \%$ of them had monocular blindness with a visual acuity (VA) of less than 3/60 in one eye. Cataract and glaucoma were the major causes of visual impairment.

Conclusion: Ensuring that all prospective drivers undergo basic vision tests, followed by prompt referral of those with visual impairment to ophthalmologists could serve as a good case detection outlet. Blinding ocular conditions could be detected early and treated appropriately. This will ultimately prevent unnecessary loss of lives and property.

\section{INTRODUCTION}

Driving can be defined as the ability to operate, control, and direct the course of a vehicle. ${ }^{1}$ It is a very important part of everyday life of majority of people. For commercial drivers, it is not just a means of livelihood, but a way of life. Commercial drivers considered to be very important especially in a developing country such as Nigeria, where majority of the people go on public road transport.

There is little doubt that the visual sense provides most of the information used by the driver, with some contribution from other senses. ${ }^{2} \mathrm{~A}$ driver's vision will largely determine how efficiently he will perform; this may consequently influence the occurrence of road traffic accidents (RTA).

Worldwide, it has been estimated that the number of people killed in RTAs each year is about 1.2 million, while the number of the injured could be as high as 50 million. ${ }^{3}$ In many low-income countries, the prevalence of traffic related injuries is such that they represent between $30 \%$ and $86 \%$ of all trauma admissions. ${ }^{4}$ They also constitute a major cause of morbidity and mortality among Nigerians. ${ }^{5,6}$

The diseases of the ocular organ and its adnexa can adversely affect the visual functions of the driver, with serious implications for road safety. The aim of this study therefore is to find out the types and prevalence of ocular and adnexal diseases among commercial intercity vehicle drivers in Ilorin, Nigeria.

\section{MATERIAls AND Methods}

This cross sectional descriptive study was carried out in Ilorin, the capital city of Kwara State, Nigeria. The study venues were the five major motor parks for CIVDs. Of the estimated 450 drivers, 399 consecutive drivers were included in the study. Written informed consent was obtained from them. This study was cleared by the Ethical and Research Committee of the University of Ilorin Teaching Hospital (UITH), Ilorin. Permission was also sought for and received from the chairmen of the National Union of Road Transport Workers (NURTW) and Road Transport Employers Association of Nigeria (RTEAN) of each motor park.

A structured questionnaire was administered as a face-to-face interview at the motor parks. solicited

${ }^{*}$ Correspondence: Dr. Bola J. Adekoya, Department of Ophthalmology, Lagos state University Teaching Hospital, Lagos, Nigeria 
information on the respondent's biodata, driving history, history of involvement in RTAs, ocular history and general medical history. Four medically qualified assistants were trained in the administration of the questionnaire and how to perform visual acuity (VA) tests. This was done in broad daylight using the Snellen (or the illiterate E) charts placed $6 \mathrm{~m}$ from the respondents. Each eye was tested separately. The unaided VA, as well as VA with pinhole (when VA is less than 6/6), were assessed and recorded.

One of the authors (BJ) conducted the ocular examinations. Colour vision was tested using the Ishihara pseudo-isochromatic plates. Visual field was tested using the confrontation method. The anterior segment was examined with the aid of a pen torch, and any abnormality discovered was recorded. Fundoscopy was performed with a Welch Allyn direct ophthalmoscope. Intra-ocular pressure (IOP) was measured with the Perkins handheld applanation tonometer, after anaesthetizing and staining the cornea with a mixture of tetracaine-fluoresceine eye drop. The tip was wiped before and after measurements with cotton wool dipped in methylated spirit and allowed to dry. Those found to require further assessment, refraction and surgery were referred to the UITH. The data collected were analysed using the Statistical Package for Social Sciences (SPSS) 12.0.1 software package, and frequency counts were generated for variables.

\section{Definition of key terms for the study}

Visual impairment: Federal Road Safety Corp (FRSC) standard for commercial drivers in Nigeria: at least 6/9 in the better eye and 6/24 in the second eye. ${ }^{7}$ Cataract was defined for the purpose of this study as the presence of lens opacity causing a reduction in VA.

Glaucoma: presence of a pale, cupped disc with a vertical cup to disc ratio of 0.7 or more.

Uncorrected refractive error: improvement in VA (when $\mathrm{VA}$ is less than 6/6) with the use of a pinhole.

Abnormal colour vision: the inability to correctly identify one or more pseudo-isochromatic plates.

Abnormal visual field: the presence of one or more abnormal quadrants on confrontation perimetry.

Ocular hypertension: IOP of $>21 \mathrm{mmHg}$ in the absence of characteristic glaucomatous optic neuropathy.

\section{RESULTS}

Three hundred and ninety-nine CIVDs participated in the study.These represent $88.7 \%$ of the total population of CIVDs in the five parks. All were men. Figure 1 shows the age distribution of respondents.
The mean age was 44.7 years +/- 10.1 as standard deviation. Almost two-thirds of the drivers were between the ages of 41 to 60 years. 264 (66.2\%) were above 40 years and $108(27.1 \%)$ were above 50 years.

One hundred and sixty-eight $(42.1 \%)$ had no form of formal education, while 149 (37.3\%) had at least primary education. Two hundred and thirty-seven (59.4\%) had been driving for more than 20 years, while $26(6.5 \%)$ had 1 5 year(s) of driving experience.

The ocular symptoms are as shown in table 1 . The most frequent complaint was that of poor near vision with $113(28.3 \%)$ drivers having difficulty with small print. Itching, redness of the eye, poor distance vision, foreign body sensation and ocular discharge also ranked high in the ocular symptoms.

Table 1. Ocular symptoms of respondents

\begin{tabular}{lcc}
\hline Ocular Symptoms & $\mathrm{n}$ & $\%$ \\
\hline Difficulty with near vision & 113 & 28.3 \\
Itching & 90 & 22.6 \\
Redness & 49 & 12.3 \\
Poor distance vision & 46 & 11.5 \\
Poor night vision & 42 & 10.5 \\
Discharge & 34 & 8.5 \\
Foreign body sensation & 30 & 7.5 \\
Double vision & 25 & 6.3 \\
Photophobia & 1 & 0.3 \\
Floaters & 1 & 0.3 \\
\hline
\end{tabular}

Three hundred and seventy-six (94.2\%) of the drivers believed they had adequate vision for driving, while 23 $(5.8 \%)$ were of the impression that their vision is not good enough for driving. Only $34(8.5 \%)$ drivers were on eye glasses to aid near work, while a smaller number 15 (3.8\%) occasionally wear sunglasses.

Table 2 reveals the ocular diagnosis in at least one eye. Presbyopia $(28.3 \%)$ was the most common ocular morbidity, followed by allergic conjunctivitis (22.6\%), pinguecula $(18.0 \%)$, ocular hypertension $(8.8 \%)$, pterygium $(8.3 \%)$, cataract $(7.8 \%)$, and uncorrected refractive error (6.0\%). Colour vision defects $(4.3 \%)$, and glaucoma $(3.8 \%)$ also ranked high.

Table 3 reveals the visual acuity of the better and second eye. Most of the drivers $(87.0 \%$ and $68.2 \%$ had VA of $6 / 6$ and above in the better eye and the second eye, respectively. Going by FRSC standards, ${ }^{7} 27$ (6.8\%) drivers had visual acuities of less than $6 / 9$ in the better eye, while $32(18.7 \%)$ had visual acuities of less than $6 / 24$ in the bad eye. Overall, 46 drivers (11.5\%) had inadequate vision for 
holding commercial vehicle license with a VA of less than $6 / 9$ in the better eye and/or less than 6/24 VA in the second eye. Thirteen (3.3\%) drivers had monocular blindness, and two of them had just found out for the first time. Majority $(77.8 \%)$ of those with visual impairment were above 40 years of age.

Table 2. Ocular findings in 399 drivers

\begin{tabular}{lcl}
\hline Ocular findings/diagnosis & $\mathrm{n}$ & $\%$ \\
\hline Presbyopia & 113 & 28.3 \\
Allergic conjunctivitis & 90 & 22.6 \\
Pingueculae & 72 & 18 \\
Ocular hypertension & 35 & 8.8 \\
Pterygium & 33 & 8.3 \\
Cataract & 31 & 7.8 \\
Uncorrected refractive error & 24 & 6 \\
Colour vision defects & 17 & 4.3 \\
Glaucoma & 15 & 3.8 \\
Corneal opacity & 5 & 1.3 \\
Age related macular degeneration & 3 & 0.7 \\
(ARMD) & & \\
Lid scar & 2 & 0.5 \\
Complications from cataract surgery & 2 & 0.5 \\
Optic atrophy & 2 & 0.5 \\
Bacterial conjunctivitis & 1 & 0.3 \\
External hordeolum & 1 & 0.3 \\
Presumed ocular toxoplasmosis (POT) & 1 & 0.3 \\
Asteroid hyalosis & 1 & 0.3 \\
\hline
\end{tabular}

Table 3. Visual acuity in the better and second eyes

\begin{tabular}{lcccc}
\hline Visual acuity & \multicolumn{2}{c}{ Better eye } & \multicolumn{2}{c}{ Second eye } \\
\cline { 2 - 5 } & $\mathrm{n}$ & $\%$ & $\mathrm{n}$ & $\%$ \\
\hline $6 / 4-6 / 6$ & 25 & 6.3 & 53 & 13.3 \\
40061 & 10 & 2.5 & 21 & 5.3 \\
40152 & 6 & 1.5 & 17 & 4.3 \\
$6 / 18$ & 7 & 1.7 & 4 & 1 \\
$6 / 24$ & 4 & 1 & 12 & 3 \\
$6 / 36$ & 0 & 0 & 5 & 12 \\
$6 / 60$ & 0 & 0 & 10 & 2.5 \\
$5 / 60-3 / 60$ & 0 & 0 & 10 & 2.5 \\
2/60-light & & & & \\
perception (LP) & 0 & 0 & 3 & 0.7 \\
No light & 399 & 100 & 399 & 100.0 \\
perception(NPL) & & & & \\
\hline TOTAL & & & & \\
\hline
\end{tabular}

Uncorrected refractive error and cataract were the usual causes of inadequate VA in the better eye, while glaucoma and cataract were more predominant in the second eye of the 399 drivers examined (see table 4).

Table 4. Causes of inadequate VA in the better and second eyes of the 399 respondents

\begin{tabular}{lcccc}
\hline Aetiology & \multicolumn{2}{c}{ Better eye } & \multicolumn{2}{c}{ Second eye } \\
\cline { 2 - 5 } & $\mathrm{n}$ & $\%$ & $\mathrm{n}$ & $\%$ \\
\hline Uncorrected refractive error & 10 & 2.3 & 4 & 1 \\
Cataract & 10 & 2.5 & 5 & 1.3 \\
Glaucoma & 1 & 0.3 & 8 & 2 \\
Pterygium & 4 & 1 & 1 & 0.3 \\
Optic atrophy & 0 & 0 & 2 & 0.5 \\
Complications from cataract & & & & \\
surgery & 0 & 0 & 2 & 0.5 \\
ARMD & 2 & 0.5 & 2 & 0.5 \\
$\begin{array}{l}\text { Presumed ocular } \\
\text { toxoplasmosis }\end{array}$ & 0 & 0 & 1 & 0.3 \\
Corneal opacity & 0 & 0 & 2 & 0.5 \\
\hline
\end{tabular}

Visual field defects were seen in four $(1.0 \%)$ and 22 (5.5\%) drivers' better and second eyes respectively. The causes of visual field defects in the better eyes were cataract (4), and advanced glaucoma (1).

Intraocular pressure measurements were performed in $377(94.5 \%)$ drivers. These could not be done in 22 drivers because, among them, 21 declined and 1 had bacterial conjunctivitis. Minimum and maximum IOPs in the better and second eyes were 6 and $40 \mathrm{mmHg}$ and 6 and $52 \mathrm{mmHg}$, respectively. The mean IOP was $16.4 \mathrm{mmHg}$ $+/-4.5$ as standard deviation in the better eyes and 16.6 $\mathrm{mmHg}+/-5.2$ as standard deviation in the second eyes.

\section{DISCUSSION}

About two-thirds (66.2\%) of the drivers studied were over 40 years, and over one-fifth were above 50 years. Older drivers were found to be worse than younger ones in tests of visual function, as well as in accident rates. ${ }^{8}$ This may be due to an age-related increase in the prevalence of ocular diseases capable of causing visual impairment and blindness among the older generation. More than $82 \%$ of all the people who are blind are 50 years or older though this age cohort represents only $19 \%$ of the world's population. ${ }^{9}$ On the contrary, some other researchers have found that age and visual health are not strongly related to driving performance and accident rates. ${ }^{10,11}$ This may be due to the fact that older drivers, especially those with 
impaired vision tend to limit their driving in order to avoid mishaps. Some may even stop driving of their own accord or when counselled.

The high percentage of drivers (42.1\%) with no formal education in this study may have a detrimental implication as far as road safety is concerned, as this may affect their ability to read and interpret road signs. There is still a pressing need to increase the literacy level of the general populace, including drivers.

Ocular examinations before issuance of driving license are not routinely done. This was revealed by the small percentage of drivers that had VA assessments at first licensing and at least once during renewal. Two of the drivers even admitted to driving without the necessary license. This is in agreement with the findings of other researchers in Nigeria. ${ }^{12,13,14}$

\section{Ocular Symptoms}

Symptoms of ocular disease among the CIVDs examined were varied. Difficulty with near work accounted for the majority of the eye complaints. It is one of the symptoms of presbyopia; a condition of gradual decline in the accommodative power of the eye. The difference between the total number of drivers above 40 years of age (264) and those with difficulty with near work (113) may be related to the literacy level, which is quite low in this study and individual's personal near vision needs, as well as the ability to cope with such needs. The prevalence of presbyopia in this study $(28.3 \%)$ is high when compared with $4.3 \%$ and $12.5 \%$ found by Falola ${ }^{15}$ and Okafor. ${ }^{14}$ The high number of older drivers in this study may also explain this. However, only about one-third of the patients with difficulty with near work wore corrective eyeglasses.

\section{Ocular Findings}

After presbyopia, allergic conjunctivitis was the most common ocular diagnosis in the drivers. It is characterized by ocular itching, redness, lacrimation, discharge and the presence of tarsal papillae. Plant pollens, dust, and smoke are potential allergens that these drivers are likely to come into contact with on a daily basis. Pterygium (8.3\%) and inflamed pingueculae $(18.0 \%)$ were also predominant findings. These two conditions are conjunctive degenerations whose pathogeneses have been linked with exposure to dry and windy conditions, as well as to ultraviolet (UV) and infrared radiation from sunlight. ${ }^{16,17}$

These risk factors characterize the typical outdoor working conditions of a driver, more so as the majority $(96.2 \%)$ of the drivers were not in the habit of wearing protective eyeglasses.

Cataract and glaucoma were found in $7.8 \%$ and $3.8 \%$ of the drivers. These are very important causes of blindness and visual impairment worldwide. ${ }^{9}$ One of the factors of the pathogenesis of cataract is excessive exposure to UV radiation. It is noteworthy that a large percentage of these drivers do not wear or believe in wearing ocular protective glasses, the majority of which would absorb most of the UV radiations that are harmful to the eye. Apart from a reduction in VA, cataract is also a potent cause of glare, reduced contrast sensitivity, and impairment of visual fields. These are all important parameters that significantly affect the performance of a driver.

Glaucoma is the second leading cause of blindness after cataract in the developing countries. ${ }^{13}$ The primary open angle type is the most prevalent among blacks. Untreated, it causes a painless and irreversible loss of vision. Peripheral visual fields are affected early while the central fields may still be preserved. Early detection with prompt and effective treatment is the key to curtailing this glaucoma. Falola ${ }^{15}$ found a rather high prevalence of $9.7 \%$, while Nwosu et al. ${ }^{18}$ reported $0.56 \%$.

Ocular diseases leading to deterioration of vision were refractive error, cataract and glaucoma. This has implication for the safety of passengers boarding these vehicles, and may lead to the unnecessary loss of life and property. Ensuring that basic vision tests are done in conjunction with adequate referral of drivers, could be a major case detection outlet for these ocular diseases, especially glaucoma, in which early detection and adequate treatment are paramount.

\section{CONCLUSION}

The common ocular morbidities seen were presbyopia, allergic conjunctivitis, pingueculae, ocular hypertension, pterygium, cataract and uncorrected refractive error. Cataract and glaucoma were the potentially blinding ocular diseases seen. This highlights the need for renewed efforts to educate vulnerable groups on these preventable causes of blindness and visual impairment, by ensuring that every potential driver at first licensing and at renewals gets the basic vision test done. Those found to have visual impairment should be referred to ophthalmologists for detailed ocular evaluation.

\section{REFERENCES}

1. Driving. Oxford Advanced Learner's Dictionary. Fifth edition. Oxford: A S Hornsby, 1995: 356.

2. Taylor JF. Vision and driving. Practitioner 1982; 226: 885-9.

3. World report on Road Traffic Injury Prevention. World Health Organization. Geneva, 2004. Available a t w w w . w ho.in t/ w orld - h e a l t h - 
day/2004/infomaterials /world_report/en/ Assessed $13^{\text {th }}$ November 2007.

4. Odero W, Garner P, Zwi A. Road traffic injuries in developing countries: a comprehensive review of epidemiological studies. Tropical Medicine and International Health 1997; 2: 445-460.

5. Adesunkanmi AR, Oginni LM, Oyelami OS, Badmus OS. Epidemiology of childhood injury. J Trauma 1998; 44: 506-12.

6. Solagberu BA, Duze AT, Ofoegbu CPK, Adekanye AO, Odelowo EOO. Surgical morbidity and mortality pattern in the accident and emergency room - a preliminary report. Afr J Med Sci. 2000; 29: 315-8.

7. Agunloye O. Guidelines for the National Drivers Licence Scheme. Public Education Department Headquarters, Lagos, Federal Road Safety Commission 1990: 6-9.

8. Davison PA. Interrelationship between British drivers visual abilities, age and road accidents histories. Ophthal Physiol Opt 1985; 5: 195-204.

9. Resnikoff S, Pascolini D, Etya'ale D, Kocur I, Pararajasegaram R, Pokharel GP, Mariotti SP. Global data on visual impairment in the year 2002. Bulletin of the World Health Organization 2004; 82: 844-51.

10. Keeffe JE, Jin CF, Weih LM, McCarty CA, Taylor HR. Vision impairment and older drivers: who's driving? Br J Ophthalmol 2002 October; 86: 1118-1121.

11. McCloskey LW, Koepsell TD, Wolf ME, Buchner DM. Motor vehicle collision injuries and sensory impairment of older drivers. Age Ageing 1994; 23: 26773.

12. Nwosu SN. Visual impairment and road traffic accident in Nigeria professional drivers. Orient J Med 1991; 3: 110-2.

13. Oladehinde $\mathrm{MK}$, Adeoye AO, Adegbehingbe BO, Onakoya AO. Visual functions of commercial drivers in relation to road accidents in Nigeria. Indian J Occup Environ Med 2007; 11: 71-5.

14. Okafor CF. Visual survey of Nigerian Police Force Drivers. Unpublished dissertation. Lagos: National Postgraduate Medical College of Nigeria. 1992: 35-39.

15. Falola A. A survey of the visual status of Nigerian army drivers in Lagos area. Unpublished dissertation. Lagos: National Postgraduate Medical College of Nigeria, May 2000.

16. Saw SM, Tan D. Pterygium: prevalence, demography and risk factors. Ophthalmic Epidemiol 1999; 6: 219-28.

17. Durkin SR, Abhary S, Newland HS, Selva D, Aung T, Casson RJ. The prevalence, severity and risk factors for pterygium in central Myanmar: the Meiktila Eye Study. Br J Ophthalmol 2008; 92: 25-9.

18. Nwosu SNN, Osuntokun O, Ajayi BJK. Prevalence of subnormal vision among government motor vehicle drivers in Oyo State. Nig Med J 1991; 21: 51-53. 